Published as Karen N. Scott, "Ocean Acidification: A Due Diligence Obligation under the LOSC?” 35 (2020) International Journal of Marine and Coastal Law 382 - 408

\title{
Ocean Acidification: A Due Diligence Obligation under the LOSC?
}

\author{
Karen N. Scott \\ University of Canterbury, New Zealand
}

Abstract

This article explores the extent to which ocean acidification is adequately addressed by the law of the sea. It will assess the various obligations under Part XII of the 1982 United Nations Convention of the Law of the Sea (LOSC) to prevent, reduce and control pollution of the marine environment, and analyse the extent to which these obligations appropriately address ocean acidification. This article argues that LOSC Parties are subject to a due diligence obligation under Part XII of the Convention to prevent, reduce and control ocean acidification, and that this obligation is not satisfied by simply complying with their obligations under the UNFCCC, unless those actions also deliberately address ocean acidification. This article goes on to examine whether and to what extent ocean acidification should be factored into decision-making associated with marine planning, fisheries management and area-based protection under the law of the sea.

\section{Key Words}

Ocean acidification, due diligence, pollution 
Published as Karen N. Scott, "Ocean Acidification: A Due Diligence Obligation under the LOSC?" 35 (2020) International Journal of Marine and Coastal Law 382 - 408

\section{Introduction}

Ocean acidification ${ }^{1}$ refers to the lowering of ocean $\mathrm{pH}$ as a consequence of changes in ocean chemistry arising from increased levels of carbon dioxide $\left(\mathrm{CO}_{2}\right)$ being drawn down into the oceans from the atmosphere ${ }^{2}$ and is a problem concurrent with, rather than a consequence of, climate change. Although we now have a good understanding of the processes of ocean acidification, we know far less about the potential impact of a change in ocean $\mathrm{pH}$ on species and ecosystems. Research does indicate however, that ocean acidification may have significant detrimental impacts on calcifying organisms and reef ecosystems for example, ${ }^{3}$ and some attempts have been made to quantify its implications for the blue economy. ${ }^{4}$

\footnotetext{
${ }^{1}$ University of Canterbury, New Zealand. This article draws on and develops research previously published as Karen N. Scott, “Ocean Acidification and Sustainable Development Goal 14: A Goal but No Target?” in Myron H. Nordquist, John Norton Moore, and Ronan Long (eds), The Marine Environment and United Nations Sustainable Development Goal 14: Life below Water ((Koninklijke Brill, Leiden) (2018) 323 - 341. It was presented at a workshop on The Law of the Sea and Climate Change. Part of the Solutions or Representing Constraints? held at K.G. Jebsen Centre for the
} Law of the Sea (JCLOS), UiT The Arctic University of Norway, Tromsø, 28 - 29 January 2019. The author acknowledges the helpful comments on this paper made by Professor Alan Boyle and other participants at the workshop and the funding provided by the K.G Jebsen Centre for the Law of the Sea. Any errors remain the responsibility of the author alone.

2 R Zeebe et al, ‘Carbon Emissions and Acidification' (2008) 321 Science 51 - 52.

${ }^{3}$ See the literature cited in the section below.

${ }^{4}$ See for example L Rodrigues, J van den Bergh and A Ghermandi, 'Socio-economic impacts of ocean acidification in the Mediterranean Sea' (2013) 38 Marine Policy 347 - 456; A Speers et al, 'Impacts of climate change and ocean acidification on coral reef fisheries: An integrated ecological-economic model' (2016) 128 Ecological Economics 33 43; J Ekstrom et al, 'Vulnerability and adaptation of US shellfisheries to ocean acidification' (2015) 5 Nature Climatic Change 207; A Punt et al, 'Evaluating the impact of ocean acidification on fishery yields and profits: The example of red king crab in Bristol Bay' (2014) 285 Ecological Modelling 39 - 53; D Narita and K Rehdanz, 'Economic impact of ocean acidification on shellfish production in Europe' (2017) 60 Journal of Environmental Planning and Management 500 
Published as Karen N. Scott, "Ocean Acidification: A Due Diligence Obligation under the LOSC?” 35 (2020) International Journal of Marine and Coastal Law 382 - 408

Until very recently, ocean acidification was largely ignored by the climate change regime established under the auspices of the 1992 United Nations Framework Convention on Climate Change (UNFCCC), ${ }^{5}$ despite its principal cause being $\mathrm{CO}_{2}$ emissions. Simultaneously however, ocean acidification is also not directly addressed by instruments regulating the law of the sea and marine pollution in particular. Bridging and, to a very limited extent, filling the gaps between these regimes are an increasing number of soft commitments and targets such as Sustainable Development Goal 14.3 adopted in $2015 .^{6}$ Although ocean acidification is an issue that is subject to a classic regime complex - parallel but functionally overlapping instruments - this article will focus on one part of that regime complex: the law of the sea. It will explore the various obligations under Part XII of the 1982 United Nations Convention of the Law of the Sea (LOSC) ${ }^{7}$ to prevent, reduce and control pollution of the marine environment, and assess the extent to which these obligations appropriately address ocean acidification. Part XII of LOSC constitutes a framework agreement, which notably draws on and incorporates external standards in respect of pollution prevention and control. This article will analyse whether the standards developed under the UNFCCC regime, in particular, comprise 'international standards' for the purposes of Article 212 of LOSC. This article will argue that LOSC Parties are in fact subject to a due diligence obligation under Part XII of the Convention to prevent, reduce and control ocean acidification, and that this obligation is not satisfied by simply complying with their obligations under the UNFCCC, unless those actions also deliberately address ocean acidification. Pollution prevention comprises just

\footnotetext{
- 518; L Mathis et al, ‘Ocean acidification risk assessment for Alaska’s fishery sector’ (2015) 136 Progress in Oceanography $71-92$.

${ }^{5}$ United Nations Framework Convention on Climate Change (9 May 1992, in force 21 March 1994) 1771 UNTS 107 (UNFCCC).

${ }^{6}$ UNGA Res 70/1 Transforming our world: the 2030 Agenda for Sustainable Development (15 September 2015).

7 United Nations Convention on the Law of the Sea (Montego Bay, 10 December 1982, in force 16 November 1994) 1833 UNTS 397 (LOSC).
} 
Published as Karen N. Scott, “Ocean Acidification: A Due Diligence Obligation under the LOSC?” 35 (2020) International Journal of Marine and Coastal Law 382 - 408

one part of the ocean acidification regime complex, and in the penultimate section of this article the question of whether and to what extent ocean acidification should be factored into decisionmaking associated with marine planning, fisheries management and area-based protection will be briefly assessed. Finally, this article will conclude with more general observations on the opportunities and constraints of the law of the sea in responding to ocean acidification.

\section{Ocean Acidification}

Ocean pH was remarkably stable, at approximately 8.2 for over 800,000 years, ${ }^{8}$ until the onset of the Industrial Revolution in the eighteenth century. Over the last 200 years ocean $\mathrm{pH}$ has decreased by $0.1 \mathrm{pH}$ units, ${ }^{9}$ the equivalent of an increase in ocean acidity of about 30 percent. $^{10}$ Ocean acidification is not an impact of climate change per se but a consequence of a common cause: an excess of carbon dioxide $\left(\mathrm{CO}_{2}\right)$ in the atmosphere, subsequently absorbed by the oceans. ${ }^{11}$ Atmospheric concentrations of $\mathrm{CO}_{2}$ have risen from approximately $280 \mathrm{ppm}$ in 1750 to over 400 ppm today. ${ }^{12}$ The oceans are the most important sink for $\mathrm{CO}_{2}$, storing 50 times more

\footnotetext{
${ }^{8} \mathrm{C}$ Turley and J Gattuso, 'Future biological and ecosystem impacts of ocean acidification and their socioeconomicpolicy implications' (2012) 4 Current Opinion in Environmental Sustainability 278 - 286, at p. 278.

9 V Rérolle, C Floquet, M Mowlem, 'Seawater-pH measurements for ocean-acidification observations' (2012) 40 Trends in Analytical Chemistry 146 - 157, at p. 146.

10 S Dupont and H Pörner, 'A snapshot of ocean acidification research' (2013) 160 Mar. Biol. 1765 - 1771, at p. 1765.

11 S Doney et al, 'Ocean Acidification: The Other $\mathrm{CO}_{2}$ Problem' (2009) Annual Review of Marine Science 169 - 192, at p. 170.

${ }^{12}$ WMO, Greenhouse Gas Bulletin No. 12 (24 October 2016) available at: https://ane4bf-datap1.s3-eu-west1.amazonaws.com/wmocms/s3fspublic/GHG Bulletin 12 EN web JN161640.pdf?aZaKZhdpDfJdmHvtbSvLwbj6zb PWwdz.
} 
Published as Karen N. Scott, "Ocean Acidification: A Due Diligence Obligation under the LOSC?” 35 (2020) International Journal of Marine and Coastal Law 382 - 408

carbon dioxide than the atmosphere, ${ }^{13}$ and approximately half of all anthropogenic fossil fuel emissions since the beginning of the Industrial Revolution. ${ }^{14}$ Today around 30 percent of all anthropogenic $\mathrm{CO}_{2}$ is drawn down into the oceans annually ${ }^{15}$ and about half of this is stored in the upper ten percent of the oceans. ${ }^{16}$ Although $\mathrm{CO}_{2}$ is the primary cause of ocean acidification, it is not the only cause. Other greenhouse gases such as $\mathrm{SO}_{x}, \mathrm{NO}_{\mathrm{x}}$ and $\mathrm{NH}_{3}$ are now known to contribute to its cause, ${ }^{17}$ and land-based runoff, primarily from agriculture, may also have significant localised impacts on ocean $\mathrm{pH} .^{18}$

A decrease in ocean $\mathrm{pH}$ causes a decrease in the saturation of calcium carbonate $\left(\mathrm{CaCO}_{3}\right)$ in seawater, and $\mathrm{CaCO}_{3}$ is the principal compound in the shells and skeletons of many marine species. ${ }^{19}$ The effect of ocean acidification is global but highly variable in terms of its regional impacts. Research suggests that its impact is greatest at the surface of the oceans, ${ }^{20}$ and higher

\footnotetext{
${ }^{13}$ M Rhein et al, 'Observations: Ocean' in T F Stocker et al (eds), Climate Change 2013: The Physical Science Basis. Contribution of Working Group I to the Fifth Assessment Report of the Intergovernmental Panel on Climate Change (Cambridge,
} Cambridge University Press 2013) 255, at p. 260 (hereinafter, IPCC Fifth Assessment Report).

14 The First Global Integrated Marine Assessment (World Ocean Assessment I) by the Group of Experts of the Regular Process under the auspices of the United Nations General Assembly and its Regular Process for Global Reporting and Assessment of the State of the Marine Environment, including Socioeconomic Aspects (2016) available at:

http://www.un.org/Depts/los/global reporting/WOA RegProcess.htm ch 5, 17 [hereinafter, WOA I].

15 IPCC Fifth Assessment Report (n 13) at p. 260.

${ }^{16}$ WOA I (n 14) chapter 5 at p. 17.

${ }^{17}$ K. Hunter, P. Liss, V. Surapipith et al, 'Impacts of anthropogenic SOx, NOx and NH3 on acidification of coastal waters and shipping lanes’ (2011) 38 Geophysical Research Letters, L13602.

${ }^{18}$ W. Cai, X. Hu, W. Huang et al, ‘Acidification of subsurface coastal waters enhanced by eutrophication' (2011) 4 Nature Geoscience, November 2011766 - 770.

${ }^{19}$ B. Hönisch, A. Ridgwell, D. Schmidt et al, ‘The Geological Record of Ocean Acidification' (2012) 335 Science 1058 -1063 , at p. 1059.

${ }^{20}$ G. G. Tarling, V. Peck, P. Ward et al, 'Effects of acute ocean acidification on spatially-diverse polar pelagic foodwebs: Insights from on-deck microcosms’ (2016) 127 Deep-Sea Research II 75 - 92, at p. 75. 
Published as Karen N. Scott, "Ocean Acidification: A Due Diligence Obligation under the LOSC?” 35 (2020) International Journal of Marine and Coastal Law 382 - 408

latitude regions such as the Arctic and Antarctic are especially vulnerable as $\mathrm{CO}_{2}$ is absorbed more easily at lower water temperatures. ${ }^{21}$ The exposure of Polar ecosystems to ocean acidification is compounded by the low energetic cost adaptation of species that allows them to survive at low temperatures, but which reduces their capacity to adapt to fast-changing environmental conditions. ${ }^{22}$ Species most at risk from ocean acidification are calcifying organisms such as pteropods, ${ }^{23}$ shelled molluscs ${ }^{24}$ and coral reef ecosystems. ${ }^{25}$ Moreover, lower ocean pH levels has also been linked to the phenomenon of coral bleaching, ${ }^{26}$ which is primarily caused by an increase in ocean temperatures. ${ }^{27}$ The impact of a lower ocean $\mathrm{pH}$ on fish species is under-researched, but some experiments indicate that low $\mathrm{pH}$ levels may damage key organs in the larvae of yellowfin

${ }^{21}$ Ibid., at p. 76.

${ }^{22}$ P. Thor, A. Bailey, C. Halsband et al, 'Seawater pH Predicted for the Year 2100 Affects the Metabolic Response to Feeding in Copepodites of the Arctic Copepod calanus glacialis' (December 19, 2016) POLS ONE

DOI:10.1371/journal.pone.0168735; P. Matson, T. Martz and G. Hofmann, 'High-frequency observations of pH under the Antarctic sea ice in the southern Ross Sea' (2011) 23 Antarctic Science 607 - 613, at p. 612.

${ }^{23} \mathrm{~J}$. Orr, et al, 'Anthropogenic ocean acidification over the twenty-first century and its impact on calcifying organisms' (2005) 437 Nature 681 - 686; N. Bednaršek, et al, 'Pteropods on the edge: Cumulative effects of ocean acidification, warming, and deoxygenation' (2016) 145 Progress in Oceanography 1 - 24.

${ }^{24} \mathrm{~J}$. Ekstrom, et al, 'Vulnerability and adaptation of US shellfisheries to ocean acidification' (March 2015) 5 Nature Climate Change $207-214$.

25 O. Hoegh-Guldbert, et al, 'Coral Reefs Under Rapid Climate Change and Ocean Acidification' (2007) 318 Science 1737 - 1742. For example, calcification of the Great Barrier Reef has decreased by around 21 percent between 1988 and 2003. See S. Doney, et al, (n. 11) at p. 175.

${ }^{26}$ K.R.N. Anthony et al, 'Ocean acidification causes bleaching and productivity loss in coral reef builders' (2008) 105

(45) PNAS 17442 - 17446; P.L. Jokiel et al, 'Ocean acidification and calcifying reef organisms: a mescocosm investigation' (2008) 27 Coral Reefs $473-483$.

${ }^{27}$ See Ove Hoegh-Guldberg, 'Climate change, coral bleaching and the future of the world's coral reefs' (1999) 50

Mar. Freshwater Res. 839 - 866. 
Published as Karen N. Scott, "Ocean Acidification: A Due Diligence Obligation under the LOSC?” 35 (2020) International Journal of Marine and Coastal Law $382-408$

tuna $^{28}$ and slow the development of embryos and larvae. ${ }^{29}$ Research has also found evidence that some fish become less predator adverse, ${ }^{30}$ and less able to distinguish between predator and nonpredator odours ${ }^{31}$ or to sense predators. ${ }^{32}$ More generally, ocean acidification reduces the capacity of the ocean to absorb $\mathrm{CO}_{2}$, jeopardising the long-term function of the ocean as a $\mathrm{CO}_{2}$ sink. ${ }^{33}$

It is predicted that without a significant decrease in the emission of $\mathrm{CO}_{2}$ (and other greenhouse gases) ocean $\mathrm{pH}$ could decrease to between 7.9 and 7.7 by $2100 .{ }^{34}$ Information on the likely impact of increased ocean acidification on ecosystems and species is limited by the fact that research to date is based primarily on laboratory experiments, often assuming very high levels of $\mathrm{CO}_{2}$ emissions beyond even worst-case scenarios, ${ }^{35}$ limited mesocosms, and observations drawn from historic high $\mathrm{pH}$ environments. ${ }^{36}$ Research to date indicates that impacts will be variable with

${ }^{28}$ A. Frommel et al, 'Ocean acidification has lethal and sub-lethal effects on larval development of yellowfin tuna, Thunnus albacares (2016) 482 Journal of Experimental Marine Biology and Ecology 18 - 24.

${ }^{29}$ K. Verkaik, J. Hamel and A. Mercier, 'Impact of ocean acidification on reproductive output in the deep-sea annelid Ophryotrocha sp. (Polychaeta: Dorvilleidae)' (2017) 137 Deep-Sea Research II 368 - 376.

${ }^{30} \mathrm{P}$. Munday et al, 'Selected mortality associated with variation in $\mathrm{CO}_{2}$ tolerance in a marine fish' (2013) Ocean Acidification $1-5$.

31 T. Branch, B. DeJoseph, L. Ray et al, 'Impacts of ocean acidification on marine seafood' (2013) 28 Trend in Ecology and Evolution 178 - 186, at p. 180.

32 P. Munday, D. Dixson, M. McCormick et al, 'Replenishment of fish populations is threatened by ocean acidification’ (July 2010) 107 PNAS 12930 - 12934.

${ }^{33}$ V. Rérolle, C. Floquet, M. Mowlem (n 9) at p. 146.

${ }^{34}$ C. Turley and J. Gattuso (n 8) at p. 278.

${ }^{35}$ For example, in the experiment carried out by Munday et al in which the authors demonstrated a dramatic decrease in the survival of larval fish an assumption of $\mathrm{CO}_{2}$ levels of between 700 and 850ppm was made. See P. Munday et al (n 32).

${ }^{36}$ C. Turley and J. Gattuso (n 8) at p. 278. 
Published as Karen N. Scott, "Ocean Acidification: A Due Diligence Obligation under the LOSC?” 35 (2020) International Journal of Marine and Coastal Law 382 - 408

substantial differences in the way species, ${ }^{37}$ including corals, respond. ${ }^{38}$ For example, in some experiments phytoplankton do not appear to be particularly affected by $\mathrm{pH}$ changes of the order predicted ${ }^{39}$ and indeed, are capable of adapting to a higher $\mathrm{CO}_{2}$ environment. ${ }^{40}$ Even some species of coral $^{41}$ and Antarctic sea urchins ${ }^{42}$ have been found to be resilient to $\mathrm{pH}$ changes. In one experiment for example, one group of copepod species actually increased in biomass by around 30 percent under elevated $\mathrm{CO}_{2}$ conditions whereas another species decreased in biomass under the same conditions. ${ }^{43}$ Some experiments have even found positive impacts as a consequence of ocean acidification, such as an increase in the capacity of seagrasses to sequester $\mathrm{CO}_{2}{ }^{44}$ and even a

${ }^{37}$ I. E. Hendriks, C. M. Durart, M. Álvarez, 'Vulnerability of marine biodiversity to ocean acidification: A metaanalysis’ (2010) 86 Estuarine, Coastal and Shelf Science 157 - 164, at p. 161.

${ }^{38} \mathrm{~J}$. Kavousi et al, 'Colony-specific investigations reveal highly variable responses among individual corals to ocean acidification and warming’ (2015) 109 Marine Environmental Research 9 - 20; J. Kavousi et al, ‘Colony-specific calcification and mortality under ocean acidification in the branching coral Montipora digitata' (2016) 119 Marine Environmental Research 161 - 165; John M. Pandolfi, Sean R. Connolly, Dustin J. Marshall, 'Projecting Coral Reef Futures Under Global Warming and Ocean Acidification’ (2011) 333 Science 418 - 422.

39 T. Eberlein et al, 'Effects of ocean acidification on primary production in a coastal North Sea phytoplankton community' (2017) 12(3) PLoS ONE e0172594.

${ }^{40}$ K. Lohbeck, U. Riebesell and T. Reusch, 'Adaptive evolution of a key phytoplankton species to ocean acidification' (2012) 5 Nature Geoscience 346 - 351.

${ }^{41}$ P. Edmunds and A. Yarid, 'The effects of ocean acidification on wound repair in the coral Porites spp.' (2017) 486 Journal of Experimental marine Biology and Ecology 98 - 104.

${ }^{42}$ E. Jones et al, 'Ocean acidification and calcium carbonate saturation states in the coastal zone of the West Antarctic Peninsula' (2017) 139 Deep-Sea Research II 181 - 194, at p. 188.

${ }^{43} \mathrm{~J}$. Taucher, M. Haunost, T. Boxhammer et al, 'Influence of ocean acidification plankton community structure during a winter-to-summer succession: An imaging approach indicates that copepods can benefit from elevated $\mathrm{CO}_{2}$ via indirect food web effects' (2017) 12(2) PLoS ONE e0169737.

${ }^{44}$ S. Garrard and N. Beaumont 'The effect of ocean acidification on carbon storage and sequestration in seagrass beds; a global and UK context' (2014) 86 Marine Pollution Bulletin 138 - 146. 
Published as Karen N. Scott, "Ocean Acidification: A Due Diligence Obligation under the LOSC?” 35 (2020) International Journal of Marine and Coastal Law $382-408$

reduction in the release of $\left(\mathrm{N}_{2} 0\right)$ into the atmosphere. ${ }^{45}$ However, the fact that individuals may demonstrate resilience to lower ocean $\mathrm{pH}$ does not rule out other negative impacts relating to range, behaviour or ecosystem function, ${ }^{46}$ and an absence of identified impacts over the short term does not mean that there are no longer-term impacts which have yet to be observed by scientists. ${ }^{47}$ Moreover, although it is known that there is significant spatial variability in the drawdown of $\mathrm{CO}_{2},{ }^{48}$ $\mathrm{pH}$ dynamics are more generally poorly understood. ${ }^{49}$ Furthermore, limitations in scientific knowledge about ocean ecosystems more generally impact on the ability to know or even to predict the consequences of greater ocean acidity. For example, the majority of coral species are actually found below a depth of 50 metres, and these ecosystems are generally under-monitored so the impacts of a lower ocean $\mathrm{pH}$ on these species are simply not known. ${ }^{50}$ Very recent research has nevertheless demonstrated the potential catastrophic impact of a significant change in ocean $\mathrm{pH}$ : in a 2019 study, Henehan et al argue that the Chicxulub bolide impact that coincides with mass

\footnotetext{
$45 \mathrm{~A}$. Rees et al, 'The inhibition of $\mathrm{N}_{2} \mathrm{O}$ production by ocean acidification in cold temperature and polar waters' (2016) 127 Deep-Sea Research II $93-101 . \mathrm{N}_{2} 0$ is approximately 300 percent more potent than $\mathrm{CO}_{2}$ as a greenhouse gas.

${ }^{46}$ S. Widdicombe and J. Spicer, 'Predicting the impact of ocean acidification on benthic biodiversity: What can animal physiology tell us?’ (2008) 366 Journal of Experimental Marine Biology 187 - 197, at p. 188.

${ }^{47} \mathrm{~J}$. Godbold and M. Solan, 'Long-term effects of warming and ocean acidification are modified by seasonal variation in species responses and environmental conditions' (2013) 368 Phil Trans R Soc B 20130186.

${ }^{48}$ E. Jones et al (n 42) at p. 182.

${ }^{49}$ P. Matson, T. Martz and G. Hofmann (n 22) at p. 607.

${ }^{50}$ J. Roberts and S. Cairns, 'Cold-water corals in a changing ocean' (2014) 7 Current Opinion in Environmental

Sustainability $118-126$, at p. 124.
} 
Published as Karen N. Scott, "Ocean Acidification: A Due Diligence Obligation under the LOSC?” 35 (2020) International Journal of Marine and Coastal Law 382 - 408

extinction at the Cretacecous-Paleogene boundary caused rapid ocean acidification, which resulted in long-lasting ecological collapse in the oceans. ${ }^{51}$

\section{The Ocean Acidification Regime Complex}

Ocean acidification is not directly regulated by any one global regime. The causes of ocean acidification on the other hand are indirectly managed - to a greater or lesser extent - by several regimes with a mandate to manage atmospheric and oceans pollution, and the conservation of biodiversity. The 1992 UNFCCC provides the global framework for managing emissions of greenhouse gases as well as adaptation to climate change. The 1982 LOSC requires Parties to address pollution of the oceans in Part XII of the Convention. The 1992 CBD imposes broad obligations on Parties to conserve biological diversity. At the regional level soft targets or recommendations have been developed within Arctic and Antarctic regimes and, more specifically, binding targets have been adopted under the auspices of the 1999 Protocol to Abate Acidification, Eutrophication and Ground-level Ozone (1999 Acidification Protocol) ${ }^{52}$ to the 1979 Convention on Long- range Transboundary Air Pollution (LRTAP) ${ }^{53}$ in Europe and North America.

Ocean acidification is thus governed by a 'regime complex', which may be defined as functionally overlapping parallel regimes and institutions that are non-hierarchical but which

\footnotetext{
51 Michael J. Henehan, Andy Ridgwell, Ellen Thomas et al, 'Rapid ocean acidification and protracted Earth system recovery followed the end-Cretaceous Chicxulub impact' (October 2019) Proceedings of the National Academy of Sciences, 201905989; DOI:10.1073/pnas.190598911.

521999 Protocol to Abate Acidification, Eutrophication and Ground-level Ozone to the 1979 Convention on Longrange Transboundary Air Pollution (as amended in 2012) (Gothenburg) available at: http://www.unece.org/env/lrtap/multi h1.html (entered into force 17 May 2005).

53 Convention on Long-range Transboundary Air Pollution (13 November 1979, in force 16 March 1983 ) 18 ILM 1442.
} 
Published as Karen N. Scott, "Ocean Acidification: A Due Diligence Obligation under the LOSC?” 35 (2020) International Journal of Marine and Coastal Law 382 - 408

nevertheless affect one another's sphere of operations. ${ }^{54}$ In order for a regime complex to be effective, meaningful connections and linkages must be created between regimes in order to create a coherent network of regulatory control. Notably, it is soft law norms and targets that are developing within the interstices between regimes, and which are simultaneously connecting and developing a mandate within those regimes in order to address changing ocean $\mathrm{pH}$. There are however significant structural limitations in relying on non-binding instruments as a foundation for a binding regime.

\section{Aims and Aspirations: Interstitial Soft Law Norms and Ocean Acidification}

Instruments that directly address ocean acidification are thus far largely non-binding and aspirational in nature. The United Nations General Assembly (UNGA), in Sustainable Development Goal (SDG) 14.3 adopted in 2015, for example, urges all States to 'minimise and address the impacts of ocean acidification, including through enhanced scientific cooperation at all levels. ${ }^{55}$ At the UN Oceans Conference held in 2017 to support the implementation of SDG 14, a register of voluntary commitments from states and other entities (including companies, NGOs and cities) was established. ${ }^{56}$ As of October 2019, 260 commitments (out of a total of 1573) were registered under the SDG 14.3 goal. ${ }^{57}$ SDG 14.3 builds on UNGA Resolution 66/288 The Future $W$ e Want (2012), which called for collective action to prevent further ocean acidification

\footnotetext{
54 See further K. J. Atler and S. Meunier, 'The Politics of International Regime Complexity' (2009) 7 Perspectives on Politics 13 - 24; T. Gehring and B. Faude, 'The Dynamics of Regime Complexes: Microfoundations and Systemic Effects' (2013) 19 Global Governance 119 - 130; and K. Raustiala and D. G. Victor, 'The Regime Complex for Plant Genetic Resources' (2004) 58 International Organisation 277 - 309.

55 UNGA Res. 70/1 Transforming our world: the 2030 Agenda for Sustainable Development (15 September 2015).

${ }^{56}$ See https://oceanconference.un.org/commitments/.

${ }^{57}$ Ibid.
} 
Published as Karen N. Scott, "Ocean Acidification: A Due Diligence Obligation under the LOSC?” 35 (2020) International Journal of Marine and Coastal Law 382 - 408

and to take steps to promote ecosystem resilience. ${ }^{58}$ Ocean acidification has been identified as an issue of serious concern in UNGA resolutions adopted annually on the oceans and the law of the sea since 2007, ${ }^{59}$ and the 2017 UN Secretary General's Report on Oceans and the Law of the Sea was devoted to the threats climate change and ocean acidification pose to the oceans, emphasising synergies between and the need to deliberately connect instruments with mandates relating to climate change, the oceans and sustainable development. ${ }^{60}$ The eighteenth meeting of the United Nations Open-ended Informal Consultative Process on Oceans and the Law of the Sea held in May 2017 focused on 'the effects of climate change on oceans ${ }^{61}$ and ocean acidification was recognised as one of many cumulative threats to the ocean environment. ${ }^{62}$ The meeting also emphasised the importance of strong inter-agency coordination, and advocated the use of UNOceans to promote coordination and coherence of UN agencies with oceans-related mandates. ${ }^{63}$

Soft obligations relating to ocean acidification have also been developed by the Parties to the 1992 CBD in Target 10 of the 2010 Aichi Biodiversity Targets, which calls on States to minimise the impacts of climate change or ocean acidification on coral reefs and other vulnerable ecosystems

\footnotetext{
58 UNGA Resolution 66/288 The Future We Want (2012) at [166].

${ }^{59}$ For example, in UNGA Res. $71 / 257$ (2016) Oceans and the Law of the Sea, ocean acidification was noted as an issue of serious concern and states were urged to take global and regional action to combat its impacts (see the preamble and [186], [187] and [189]).

${ }^{60}$ Report of the Secretary General, Oceans and the Law of the Sea (A/72/70) (6 March 2017).

${ }^{61}$ Report on the work of the United Nations Open-ended Informal Consultative Process on Oceans and the Law of the Sea at its eighteenth meeting A72/95 (16 June 2017). In 2013 ocean acidification comprised the topic for the fourteenth United
} Nations Open-ended Informal Consultative Process on Oceans and the Law of the Sea. See Report of the work of the United Nations Open-ended Informal Consultative Process on Oceans and the Law of the Sea at its fourteenth meeting A68/159 (17 July 2013).

62 Ibid., at [21].

${ }^{63}$ Ibid., at [112 - 114]. 
Published as Karen N. Scott, "Ocean Acidification: A Due Diligence Obligation under the LOSC?” 35 (2020) International Journal of Marine and Coastal Law 382 - 408

so as to maintain their integrity and ecosystem function by $2015 .{ }^{64}$ Despite the risks posed by ocean acidification being highlighted in several CBD decisions on ocean and coastal biodiversity ${ }^{65}$ and in the two synthesis reports on ocean acidification published in 2009 and $2014,{ }^{66}$ it is clear that the goal in Target 10 has not been met.

At the regional level, more attention has been paid to date to the impacts of climate change rather than ocean acidification per se by regional fisheries management organisations (RFMOs) and regional seas conventions. An important exception to this is the Arctic Council, which commissioned the Arctic Ocean Acidification Assessment in 2013. ${ }^{67}$ The Council noted, with concern, the potential impacts of ocean acidification on marine life and people in the Arctic, and formally recognised that carbon dioxide emissions reductions are the only effective way of mitigating ocean acidification. It requested that Member States take action to monitor and assess Arctic ocean acidification, as well as mitigating and adapting to its impacts. ${ }^{68}$ Most recently, ocean acidification was noted as a challenge across the Commonwealth in the 2018 Commonwealth Blue Charter - 'Shared ocean, shared values', 69 and an Action Group on Ocean Acidification was

\footnotetext{
${ }^{64}$ Decision X/2 (2010) Strategic Plan for Biodiversity 2011 - 2020, Annex.

${ }^{65}$ See for example Decision XII/23 (2014) Ocean and Coastal Biodiversity at [6 - 10].

${ }^{66}$ Secretariat of the Convention on Biological Diversity (2014), An Updated Synthesis of the Impacts of Ocean Acidification on Marine Biodiversity (Eds: S. Hennige, J.M. Roberts \& P. Williamson). Montreal, Technical Series No. 75; Secretariat of the Convention on Biological Diversity (2009). Scientific Synthesis of the Impacts of Ocean Acidification on Marine Biodiversity. Montreal, Technical Series No. 46.

67 AMAP, 2013. AMAP Assessment 2013: Arctic Ocean Acidification. Arctic Monitoring and Assessment Programme (AMAP), Oslo, Norway.

682013 Kiruna Declaration of the Eighth Ministerial Meeting of the Arctic Council.

692018 Commonwealth Blue Charter: Shared Values Shared Oceans para. 17 available at:

https://bluecharter.thecommonwealth.org/.
} 
Published as Karen N. Scott, "Ocean Acidification: A Due Diligence Obligation under the LOSC?” 35 (2020) International Journal of Marine and Coastal Law 382 - 408

established under the leadership of New Zealand in order to improve understanding of the impact and drivers of ocean acidification and mitigation, adaptation and resilience measures. ${ }^{70}$

Finally, it is worth noting that soft targets and processes for collaboration and capacity building have also been developed by scientific and other non-governmental organisations. One hundred and twenty-two scientists adopted the Monaco Declaration in 2008 urging States to develop plans to cut emissions drastically, and to improve communication between policymakers and scientists in order to improve understanding of the impacts of ocean acidification. ${ }^{71}$ The Global Network of Scientific Academies (IAP) adopted a statement on ocean acidification in 2009, and recommended that $\mathrm{CO}_{2}$ should be reduced by 50 percent below 1990 levels by 2050 . The statement also advocated action to reduce other stressors on ocean ecosystems. ${ }^{72}$ The Ocean Acidification International Coordination Centre based in Monaco and supported by the International Atomic Energy Agency (IAEA) was established in 2012 in order to support capacity building and communication of science associated with ocean acidification. ${ }^{73}$ Furthermore, the Global Ocean Acidification Observing Network was established shortly thereafter in order to improve understanding of global ocean acidification conditions, ecosystem responses to ocean acidification and to acquire and exchange data and knowledge necessary to optimise modelling for ocean acidification and its impacts. ${ }^{74}$

\footnotetext{
70 See further at: https://bluecharter.thecommonwealth.org/action-groups/ocean-acidification/.

${ }^{71}$ Monaco Declaration, adopted at the Second International Symposium on the Ocean in a High $\mathrm{CO}_{2}$ World, Monaco, October 6 - 9 2008. Available at: https://www.iaea.org/nael/docrel/MonacoDeclaration.pdf.

722009 IAP Statement on Ocean Acidification available at: $\underline{\text { http://www.interacademies.net/File.aspx?id=9075. }}$

73 See: https://www.iaea.org/ocean-acidification/page.php?page=2178.

${ }^{74}$ See http://www.goa-on.org/ApproachAndGoals.php and Newton J.A., Feely R. A., Jewett E. B., Williamson P. \& Mathis J., 2015. Global Ocean Acidification Observing Network: Requirements and Governance Plan. Second Edition, GOA-ON, http://www.goa-on.org/docs/GOA-ON_plan_print.pdf.
} 
Published as Karen N. Scott, "Ocean Acidification: A Due Diligence Obligation under the LOSC?” 35 (2020) International Journal of Marine and Coastal Law 382 - 408

\section{The Law of the Sea and Ocean Acidification}

The law of the sea operates within the framework of the 1982 United Nations Convention on the Law of the Sea (LOSC). Part XII of the Convention addresses the marine environment, and creates a general obligation on all States to protect and preserve the marine environment, ${ }^{75}$ and to take individually or jointly all necessary measures to 'prevent, reduce and control pollution of the marine environment from any source'. ${ }^{76}$ Anthropogenic sources of $\mathrm{CO}_{2}$ can be classified as 'pollution' which, for the purposes of LOSC, is defined as substances or energy introduced directly or indirectly into the marine environment that results in or is likely to result in deleterious effects as to harm living resources and marine life. ${ }^{77}$ Whether introduced directly (as a consequence of $\mathrm{CO}_{2}$ sequestration) or indirectly (through 'natural' draw-down from the atmosphere or from ocean fertilization activities) there is little doubt that the impact of $\mathrm{CO}_{2}$ on marine life can be described as deleterious. The broad obligation to prevent, reduce and control marine pollution under Article 194 of the Convention is developed in subsequent provisions within LOSC on a sectoral basis: land-based sources; ${ }^{78}$ the atmosphere $;{ }^{79}$ offshore activities; $;{ }^{80}$ dumping; ${ }^{81}$ and vessel-source pollution. ${ }^{82}$ Rather than providing for detailed regulation within the Convention, LOSC uses the novel device of incorporating standards developed under external instruments, and applies those standards to Convention Parties. Those standards however, are highly variable ranging from

\footnotetext{
751982 LOSC, Articles 192 and 193.

761982 LOSC, Article 194(1).

771982 LOSC, Article 1(4).

781982 LOSC, Article 207.

791982 LOSC, Article 212.

801982 LOSC, Articles 208 and 209.

811982 LOSC, Article 201.

821982 LOSC, Article 211.
} 
Published as Karen N. Scott, "Ocean Acidification: A Due Diligence Obligation under the LOSC?” 35 (2020) International Journal of Marine and Coastal Law 382 - 408

detailed binding obligations in respect of vessel source pollution to soft recommendations associated with land-based sources. Unsurprisingly, there are no standards relating directly to ocean acidification itself.

Since 1982, marine environmental protection under the auspices of LOSC has developed to encompass a much broader toolbox than the control of pollution. It now includes general principles such as precaution and environmental impact assessment, as well as specialist tools such as spatial and integrated planning and area-based protection. All of these principles and tools are relevant to a greater or lesser extent to ocean acidification.

\section{Atmospheric Pollution Prevention and Ocean Acidification}

As the dominant source of ocean acidification is an excess of $\mathrm{CO}_{2}$ in the atmosphere, subsequently drawn down into the ocean, Article 212 of LOSC, which addresses pollution from or through the atmosphere, is directly applicable. The inclusion of atmospheric pollution within LOSC was advocated during negotiations in 1973, and LOSC is consequently one of the first global treaties that recognised atmospheric pollution as a source of marine pollution. ${ }^{83}$ States Party to LOSC are under an obligation to adopt laws or regulation to prevent atmospheric pollution of the marine environment in respect of territory under their sovereignty or in respect of their registered vessels or aircraft. ${ }^{84}$ In contrast to LOSC obligations relating to vessel source pollution or dumping however, States need only take into account internationally agreed rules, standards and recommended practices. ${ }^{85}$ Moreover, States need only endeavour to establish global and regional

\footnotetext{
${ }^{83}$ Kristin Bartenstein, 'Article 212' in Alexander Proelss (ed), United Nations Convention on the Law of the Sea. A Commentary (Beck, Hart, Nomos Munchen) 1443 - 1450 at p. 1445.

841982 LOSC, Article 212(1).

85 Ibid.
} 
Published as Karen N. Scott, "Ocean Acidification: A Due Diligence Obligation under the LOSC?” 35 (2020) International Journal of Marine and Coastal Law 382 - 408

rules controlling such pollution. ${ }^{86}$ Finally, States shall 'take other measures as may be necessary to prevent, reduce and control such pollution' ${ }^{87}$ a reference to non-binding measures ${ }^{88}$

Whereas instruments regulating dumping and vessel-source pollution were already in place prior to the adoption of LOSC, and thus references to international standards implicitly referenced these instruments, this was not the case for atmospheric pollution. Nevertheless, adopting a teleological approach to treaty interpretation, the reference to 'internationally agreed rules' etc. in Article 212 can be interpreted as a reference to the 1992 United Nations Convention on Climate Change (UNFCCC) and its associated instruments and other measures. However, although the overall aims of the UNFCCC, as articulated in Article 2 of the Convention, ${ }^{89}$ is clearly supportive of the objective as stipulated in Article 212 of LOSC, the focus of the UNFCCC is largely on the atmosphere as opposed to the hydrosphere. This is demonstrated by the definition of climate change itself within the UNFCCC: 'a change of climate which is attributed directly or indirectly to human activity that alters the composition of the global atmosphere and which is in addition to natural climate variability observed over comparable time periods.' 90 Substantively, in addressing emissions under the 1997 Kyoto Protocol, Annex I Parties have the flexibility of choosing from a

\footnotetext{
861982 LOSC, Article 212(3).

871982 LOSC, Article 212(2).

${ }^{88}$ Kristin Bartenstein, (n 80) at p. 1449.

89 'The ultimate objective of this Convention and any related legal instruments that the Conference of the Parties may adopt is to achieve, in accordance with the relevant provisions of the Convention, stabilization of greenhouse gas concentrations in the atmosphere at a level that would prevent dangerous anthropogenic interference with the climate system. Such a level should be achieved within a time frame sufficient to allow ecosystems to adapt naturally to climate change, to ensure that food production is not threatened and to enable economic development to proceed in a sustainable manner.' 1992 UNFCCC, Article 2.
}

901992 UNFCCC, Article 1(1) (emphasis added). 
Published as Karen N. Scott, "Ocean Acidification: A Due Diligence Obligation under the LOSC?” 35 (2020) International Journal of Marine and Coastal Law 382 - 408

'basket' of six (now seven) ${ }^{91}$ greenhouse gases in order to meet the global commitment of a reduction in greenhouse gas emissions of 5 percent below 1990 levels, ${ }^{92}$ but no specific targets have been set in respect of $\mathrm{CO}_{2}$, the principal cause of ocean acidification. Even greater flexibility is afforded to the Parties to the 2015 Paris Agreement, ${ }^{93}$ which does not specify an emissions reduction target, but instead, requires States to determine their own commitments at the national level designed to meet the Agreement's overarching objective to limit global temperature rise to $2^{0}$ $\mathrm{C}$ with the aim of limiting the rise to $1.5^{0} \mathrm{C} .^{94}$ Although both the Kyoto Protocol and the Paris Agreement encourage the enhancement of $\mathrm{CO}_{2}$ sinks, both instruments focus on forest and other land-based sinks, and essentially ignore the capacity of the ocean as a sink. ${ }^{95}$ Most importantly, although the Paris Agreement has set a target in respect of temperature rise (which may or may not be sufficient to avoid serious harm to the oceans), it has not established an equivalent target in respect of ocean $\mathrm{pH}$.

Despite these deficiencies, the climate regime is evolving to pay greater attention to the relationship between climate and the oceans, both in terms of impact and in respect of mitigation. It is notable that 70 percent of the 161 States that have submitted nationally determined contributions (NDCs) pursuant to Article 4(2) of the 2015 Paris Agreement refer specifically to marine issues. ${ }^{96}$ Fifty NDCs address ocean mitigation of climate change in addition to adaptation, ${ }^{97}$

\footnotetext{
91 The list of greenhouse gases under the 1997 Kyoto Protocol was amended in Doha in 2012. See Decision

1/CMP.8 (2012) Amendment to the Kyoto Protocol pursuant to its Article 3, paragraph 9 (the Doba Amendment).

921997 Kyoto Protocol, Article 3(1).

${ }^{93}$ Paris Agreement, (12 December 2015, in force 4 November 2016) (2016) 55 ILM 743.

942015 Paris Agreement, Article 2.

951992 UNFCCC, Article 4(2)(a) and 1997 Kyoto Protocol, Article 4(2)(a).

${ }^{96}$ N. D. Gallo, D. G. Victor and L. A. Levin, 'Ocean commitments under the Paris Agreement' (2017) 7 Nature

Climate Change $833-838$, at p. 833.

${ }^{97}$ Ibid., at p. 834.
} 
Published as Karen N. Scott, "Ocean Acidification: A Due Diligence Obligation under the LOSC?” 35 (2020) International Journal of Marine and Coastal Law 382 - 408

and actions taken to mitigate climate change, in particular, $\mathrm{CO}_{2}$ emissions, will directly or indirectly address ocean acidification. At the 2016 UNFCCC Conference of the Parties (COP 22), the ocean was designated as one of nine Global Climate Action Events, and the Global Ocean Acidification Observing Network (GOA-ON), a collaborative network of institutions undertaking research on ocean acidification processes in order to inform policy development was established. ${ }^{8}$ The States Party to the UNFCCC (along with other stakeholders, including UN Oceans,) also adopted $A$ Strategic Action Roadmap on Oceans and Climate: 2016 - 2021 setting out six policy recommendations relating to the role of the oceans in the climate, mitigation, adaptation, displacement, financing and capacity development. ${ }^{99}$ In 2017, at COP 23, the Oceans Pathway Partnership was launched, endorsing a two-track strategy to increase the consideration of oceans within UNFCCC processes and to increase action in priority areas impacting or impacted by oceans and climate change. ${ }^{100}$ Prospects for developing measures under the UNFCCC which are focussed on ocean acidification have therefore improved and, as LOSC is undoubtedly an evolving or 'living' treaty, ${ }^{101}$ such future measures will be relevant for the interpretation and application of Article 212 of the Convention.

At the regional level the only instrument adopted thus far that directly addresses ocean acidification through emissions is the LRTAP 1999 Acidification Protocol, which applies to Europe and North America. The objective of the Protocol is to control and reduce emissions of sulphur, nitrogen oxides, ammonia, volatile organic compounds and particulate matter which cause

\footnotetext{
${ }^{98}$ See Global Climate Action Event: Oceans (12 November 2016) available at: http://climateaction.unfccc.int/media/1055/gca-oceans-programme.pdf.

${ }^{99}$ B. Cicin-Sain, J. Barbiere, H. Terashima et al, Toward a Strategic Action Roadmap on Oceans and Climate: 2016 - 2021, Washington DC: Global Ocean Forum, 2016 available at:
}

https://globaloceanforumdotcom.files.wordpress.com/2013/03/strategic-action-roadmap-on-oceans-and-climatenovember-2016.pdf.

100 Source: https://cop23.com.fj/the-ocean-pathway.

${ }^{101}$ See discussion and references below. 
Published as Karen N. Scott, "Ocean Acidification: A Due Diligence Obligation under the LOSC?” 35 (2020) International Journal of Marine and Coastal Law 382 - 408

adverse effects on health and the environment, including acidification. ${ }^{102}$ The Protocol requires Parties to establish critical loads for acidity, ${ }^{103}$ which are defined as 'the maximum amount of acidifying deposition an ecosystem can tolerate in the long term without being damaged' and which in the long term 'will not cause adverse effects to the structure and functions of ecosystems ${ }^{104}$ and obligations to reduce emissions are set out in Annex II. This is important in the context of local ocean acidification, but notably provides no obligations to reduce $\mathrm{CO}_{2}$ more generally, which, as noted above, is the principal cause of ocean acidification.

Finally, Article 212(1) also refers to atmospheric pollution emitted from vessels and aircraft. In respect of ship-source atmospheric pollution binding regulation was adopted in 1997 when Annex VI was added to the $1979 / 83$ MARPOL. ${ }^{105}$ Annex VI sets standards relating to the emission of sulphur oxide (SOx) and nitrogen oxide (NOx) and subsequent amendments have strengthened those emissions standards, ${ }^{106}$ addressed ship energy-efficiency more generally ${ }^{107}$ and designated four Emission Control Areas (ECAS) where emission standards are higher. ${ }^{108}$ By virtue of Article 211(2) of LOSC these standards constitute the minimum to be applied by flag States to vessels within their registries.

\footnotetext{
1021999 Protocol to Abate Acidification, Eutrophication and Ground-level Ozone, Article 2.

103 Ibid.

1041999 Protocol to Abate Acidification, Eutrophication and Ground-level Ozone, Annex I. Methodologies for establishing critical loads are set out in Annex 1 and vary according to location (EMEP Parties and Parties in North America).

105 International Convention for the Prevention of Pollution from Ships as Modified by the Protocol of 1978 relating thereto (2 November 1973, in force 2 October 1983) 1340 UNTS 62 (MARPOL 73/78).

106 Resolution MEPC.132(53) (adopted on 22 July 2005).

${ }^{107}$ For example, all ships must develop a Ship Energy Efficiency Management Plan (SEEMP). See Resolution MEPC.203(62) (adopted on 15 July 2011).

108 These comprise: Baltic Sea area ( $\mathrm{SO}_{\mathrm{x}}$ only); North Sea area $\left(\mathrm{SO}_{\mathrm{x}}\right.$ only); North American area $\left(\mathrm{SO}_{\mathrm{x}}, \mathrm{NO}_{\mathrm{x}}\right.$ and $\left.\mathrm{PM}\right)$; and United States Caribbean Sea area $\left(\mathrm{SO}_{\mathrm{x}}, \mathrm{NO}_{\mathrm{x}}\right.$ and $\left.\mathrm{PM}\right)$.
} 
Published as Karen N. Scott, "Ocean Acidification: A Due Diligence Obligation under the LOSC?" 35

(2020) International Journal of Marine and Coastal Law 382 - 408

Land-based Pollution Prevention and Ocean Acidification

Land-based run off from agriculture and from industrial sources makes a minor contribution to ocean acidification overall, but may have significant impact in some local, coastal locations. The obligation on Parties to LOSC to address land-based sources of pollution is expressed in similar terms to their obligation in respect of atmospheric pollution. Article 207 requires Parties to generally prevent, reduce and control land-based sources of pollution, and to take other measures as may be necessary for this task. ${ }^{109}$ Parties are encouraged to harmonise policies on a regional basis and to adopt global binding standards and recommended practices taking into account regional features and the needs of developing countries. ${ }^{110}$ There is no obligation to adopt, at a national level, agreed international standards, but Parties must take into account international standards, recommendations and practices when developing national rules. ${ }^{111}$ In contrast to atmospheric pollution, there are no globally binding standards regulating land-based sources of marine pollution. Instead, the 1995 Global Programme for Action (GPA) ${ }^{112}$ establishes soft, nonbinding targets to limit the release of land-based pollutants, including nutrients, which can exacerbate local sources of acidification. Ocean acidification resulting from land-based activities was expressly identified as a threat to vulnerable developing States in the 2006 Beijing Declaration on the GPA. ${ }^{113}$ At the regional level, binding targets in respect of land-based sources of pollution

\footnotetext{
1091982 LOSC, Article 207(1) and (2).

1101982 LOSC, Article 207(3) and (4).

1111982 LOSC, Article 207(1).

112 See https://www.unep.org/gpa/.

1132006 Beijing Declaration on furthering the implementation of the Global Programme of Action for the

Protection of the Marine Environment from Land-based Activities adopted at the Intergovernmental Review

Meeting on the Implementation of the Global Programme of Action for the Protection of the Marine Environment
} 
Published as Karen N. Scott, "Ocean Acidification: A Due Diligence Obligation under the LOSC?” 35 (2020) International Journal of Marine and Coastal Law 382 - 408

have been adopted in areas such as the Mediterranean ${ }^{114}$ and North East Atlantic, ${ }^{115}$ but these are similarly more focused on localised $\mathrm{pH}$ abatement as opposed to addressing ocean acidification more generally.

The Dumping Regime and Ocean Acidification

Of indirect application to ocean acidification, is Article 210 and the dumping regime in respect of the sequestration of $\mathrm{CO}_{2}$, which if released into the marine environment may inadvertently lead to localised if not a more general change in ocean $\mathrm{pH}$, and ocean fertilization, which is deliberately designed to increase the uptake of $\mathrm{CO}_{2}$ by the oceans in order to mitigate climate change.

Parties to LOSC are obliged to apply global rules and standards in respect to activities that constitute dumping at sea to their territory and to vessels registered under their jurisdiction. ${ }^{116}$ It is accepted that the international standards are provided by the 1972 London Convention ${ }^{117}$ and 1996 Protocol to the London Convention. ${ }^{118}$ It is unclear however, whether Article 210 refers to either

from Land-based Activities, Second session, Beijing, 16-20 October 2006 (UNEP/GPA/IGR.2/7) (23 October 2006), Annex V.

1141996 Protocol for the Protection of the Mediterranean Sea against Pollution from Land-Based Sources and Activities, available at:

http://wedocs.unep.org/bitstream/handle/20.500.11822/7096/Consolidated_LBS96 ENG.pdf?sequence=5\&isAll owed $=$ y (in force 18 May 2006).

115 Convention for the Protection of the Marine Environment of the North East Atlantic (17 March 1992, in force 25 March 1998), 2354 UNTS 67, Annex I (OSPAR Convention).

1161982 LOSC, Article 210(1) and (6).

117 Convention for the Prevention of Marine Pollution by Dumping from Ships and Aircraft, (29 December 1972, in force 30 August 1975) 11 ILM (1972), 262 (London Convention).

118 Protocol to the London Convention on the Prevention of Marine Pollution by Dumping of Wastes and Other Matter, (8 November 1996, in force 24 March 2006) (1997) 35 ILM 1. 
Published as Karen N. Scott, "Ocean Acidification: A Due Diligence Obligation under the LOSC?” 35 (2020) International Journal of Marine and Coastal Law 382 - 408

the 1972 Convention or the 1996 Protocol or, possibly, to both. The 1996 Protocol adopts a different approach to managing dumping as compared to the 1972 Convention, essentially introducing a presumption against dumping subject to limited exceptions. Moreover, rules relating to both $\mathrm{CO}_{2}$ sequestration and ocean fertilization have been developed under the auspices of the Protocol rather than the Convention. Nevertheless, only 51 States have ratified the Protocol to date, and LOSC itself provides no mechanism which expressly recognises the standards developed in one instrument over another. Furthermore, although the definition of dumping in $\mathrm{LOSC}^{119}$ is broad enough to encompass the sequestration of $\mathrm{CO}_{2}$ below the sea bed or in the water column (provided sequestration takes place from a ship or platform), it clearly does not extend to ocean fertilization or other geoengineering activities that cannot constitute 'disposal' or 'placement... contrary to the aims of LOSC. It is unlikely therefore that Article 210 of LOSC can be relied on to apply the ocean fertilization regime as developed under the 1996 Protocol to all LOSC Parties.

Nevertheless, States Party to the 1996 Protocol will be bound by the regime governing ocean fertilization, once it enters into force. The formal legal basis for regulating ocean fertilization - and potentially other marine geoengineering activities - was created in 2013 through formal amendment to the Protocol. ${ }^{120}$ The deliberate transfer of $\mathrm{CO}_{2}$ from the atmosphere to the oceans in an effort to mitigate climate change - ocean fertilization - risks reducing ocean $\mathrm{pH}$, and thus may exacerbate ocean acidification. Although geoengineering is expansively defined under the 2013 amendment, ${ }^{121}$ the Protocol has, for the time being, restricted its regulatory mandate to

\footnotetext{
1191982 LOSC, Article 1(5).

${ }^{120}$ Resolution LP.4(8) on the Amendment to the London Protocol to Regulate the Placement of Matter for Ocean Fertilization and
} other Marine Geoengineering Activities (18 October 2013). This followed the more general declaration in 2008 that ocean fertilization fell within the jurisdiction of the Protocol. See Resolution LP.1 on the Regulation of Ocean Fertilization (31 October 2008).

${ }^{121}$ London Protocol, Article 1(5) bis (amendment not yet in force) defines geoengineering as 'a deliberate intervention in the marine environment to manipulate natural processes, including to counteract anthropogenic climate change 
Published as Karen N. Scott, "Ocean Acidification: A Due Diligence Obligation under the LOSC?” 35 (2020) International Journal of Marine and Coastal Law 382 - 408

geoengineering activities that involves the placement of matter into the sea from vessels, aircraft or offshore structures for the purposes of ocean fertilization; activities that are most closely related to dumping. Protocol Parties are not permitted to place any matter in the marine environment for ocean fertilization purposes unless the activity constitutes legitimate scientific research, accords with the detailed Assessment Framework set out in Annex 5 of the Protocol, and is authorized under a permit. ${ }^{122}$ As of 2019 however, only five States have ratified the 2013 amendment to the 1996 Protocol (Estonia, Finland, Netherlands, Norway and the UK). Therefore, globally, ocean fertilization activities are for practical purposes governed by the more generally applicable rules of the dumping regime, the principles on the prevention of pollution and harm to the marine environment as set out in Part XII of LOSC, and the general principles of international environmental law including precaution, the no harm principle (and due diligence), and process obligations such as environmental impact assessment. ${ }^{123}$

Of less direct relevance to ocean acidification, is the regulation of sub-seabed $\mathrm{CO}_{2}$ sequestration under the Protocol. ${ }^{124}$ In order to mitigate any risks of contamination, the Protocol requires Parties to comply with a detailed risk assessment and management framework when undertaking sub-seabed disposal activities, and must actively consider the nature of the disposal site, processes associated with disposal and potential impacts on biodiversity and habitats when

and/ or its impacts, and that has the potential to result in deleterious effects, especially where those effects may be widespread, long lasting or severe'.

122 London Protocol, Article 6bis and Annex 4 (amendment not yet in force).

${ }^{123}$ See K. N. Scott, 'International Law in the Anthropocene: Responding to the Geoengineering Challenge' (2013) 34 Michigan Journal of International Law 309 - 358, at pp. 333 - 350.

${ }^{124}$ The disposal or sequestration of $\mathrm{CO}_{2}$ in sub-seabed geological formations is now expressly permitted following an amendment to the 1996 Protocol in 2006. See 1996 London Protocol, Annex I, paras. 1.8 and 4 as inserted by Resolution LP.1(1) (2006) on the amendment to include $\mathrm{CO}_{2}$ Sequestration in sub-seabed Geological formations in Annex 1 to the London Protocol (in force 20 February 2007). 
Published as Karen N. Scott, “Ocean Acidification: A Due Diligence Obligation under the LOSC?” 35 (2020) International Journal of Marine and Coastal Law 382 - 408

carrying out an environmental impact assessment prior to disposal. ${ }^{125}$ The Protocol was further amended in 2009 so as to permit the export of $\mathrm{CO}_{2}$ within streams for disposal provided that an agreement or an arrangement has been entered into by the countries concerned confirming and allocating permitting responsibilities between the States in accordance with the Protocol. ${ }^{126}$ Direct disposal of $\mathrm{CO}_{2}$ in the water column, which would have implications for ocean $\mathrm{pH}$ is not permitted under the Protocol. In theory, sub-seabed $\mathrm{CO}_{2}$ sequestration should not contribute to ocean acidification provided the $\mathrm{CO}_{2}$ remains contained.

\section{An Independent Obligation to Prevent, Control and Mitigate Ocean Acidification?}

The common theme to have emerged from the above analysis is that whilst all States are subject to a general, mandatory obligation to 'prevent, reduce and control pollution of the marine environment' from atmospheric, land-based and other sources, that obligation appears to have little substance in the absence of associated external globally binding standards. In the context of ocean acidification, there are either no globally binding standards (in the case of land-based pollution), or those standards are not particularly well suited to ocean acidification (as in the case of atmospheric pollution). The question therefore arises whether States can be required to take

\footnotetext{
${ }^{125}$ See the Risk. Assessment and Management Framework for $\mathrm{CO}_{2}$ Sequestration in Sub-seabed Geological Structures (CS-SSGS) adopted at the $28^{\text {th }}$ Consultative Meeting of Contracting Parties under the London Convention and the $1^{\text {st }}$ Meeting of Contracting Parties under the London Protocol (30 October - 3 November 2006) (LC/SG-CO2 1/7, annex 3). Additional guidelines were adopted in 2012. See 2012 Specific Guidelines for the Assessment of Carbon Dioxide for Disposal into Sub-seabed Geological Formations (adopted 2 November 2012) (LC 34/15, annex 8).

${ }^{126}$ London Protocol, Article 6(2) as inserted by Resolution LP.3(4) on the amendment to Article 6 of the London Protocol
} (adopted on 30 October 2009). (Amendment not yet in force). See D. Langlet, 'Exporting $\mathrm{CO}_{2}$ for Sub-Seabed Storage: The Non-Effective Amendment to the London Dumping Protocol and Its Implications’ (2015) 30 International Journal of Marine and Coastal Law 395 - 417. 
Published as Karen N. Scott, "Ocean Acidification: A Due Diligence Obligation under the LOSC?” 35 (2020) International Journal of Marine and Coastal Law 382 - 408

action to address ocean acidification beyond their commitments under the climate regime in order to meet their obligations under Part XII of LOSC, in particular, under Articles 192 and 194 of the Convention. There is little doubt that there is no general obligation to refrain from all activities likely to cause ocean acidification, and any obligation under Part XII of LOSC is one of due diligence. ${ }^{127}$ The issue is therefore whether this due diligence obligation has been met where States comply with their Kyoto/ Paris commitments, or whether compliance with UNFCCC regime obligations is insufficient to discharge their LOSC obligations.

On the one hand it might be argued that the UNFCCC regime provides the lex specialis in respect of atmospheric pollution, and it would be unreasonable to expect States to go beyond their climate commitments, particularly when LOSC provides no additional guidance or standards on what would be required to comply with due diligence in this context. ${ }^{128}$ On the other hand, if it is demonstrated that UNFCCC commitments are clearly insufficient to 'prevent, reduce and control' pollution leading to ocean acidification, it would seem anachronistic to argue that compliance with those standards constitutes 'due diligence' in this context. As discussed above, although the UNFCCC regime is increasing its focus on oceans issues, ocean acidification remains largely overlooked, in contrast to climate change. The UNFCCC regime does not provide specific targets in respect of $\mathrm{CO}_{2}$ emissions and does not set a $\mathrm{pH}$ stabilisation goal. It is up to individual States to determine how they are going to contribute to limiting global temperature rise to $2 / 1.5^{\circ} \mathrm{C}$, and whilst any action taken may also, incidentally, mitigate ocean acidification, (where for example, the action is aimed at reducing $\mathrm{CO}_{2}$ emissions), it is entirely possible that States are able to comply with their obligations under the UNFCCC without addressing ocean acidification. Therefore, it is

\footnotetext{
${ }^{127}$ Responsibilities and obligations of States with respect to activities in the Area, Order of 18 May 2010, ITLOS Reports 2008-2010, p. 39 paras. $115-223$.

${ }^{128}$ See Alan Boyle, 'Climate Change, Ocean Governance and UNCLOS' in Jill Barrett and Richard Barnes (eds), Law of the Sea. UNCLOS as a Living Treaty (BICL London 2016) 211 - 230, at p. 222.
} 
Published as Karen N. Scott, "Ocean Acidification: A Due Diligence Obligation under the LOSC?” 35 (2020) International Journal of Marine and Coastal Law 382 - 408

argued here that the due diligence obligation under LOSC to 'prevent control and reduce' pollution of the marine environment caused by ocean acidification is not met by merely meeting UNFCCC commitments, except where those commitments also expressly relate to ocean acidification. This conclusion would appear to be supported by SDG 14.3 and other non-binding resolutions and decisions, that call upon States to take specific action in respect of ocean acidification distinct from and beyond their obligations under the UNFCCC regime, implicitly recognising that UNFCCC obligations do not adequately address ocean acidification. These goals and targets, albeit expressed in non-binding form, also arguably inform the content of the due diligence obligation under LOSC to address ocean acidification.

Considering Ocean Acidification in the Context of Area Conservation and Fisheries Management

The final mechanism through which the law of the sea may contribute to addressing ocean acidification is the incorporation of ocean acidification into decision-making associated with integrated and marine spatial planning, environmental impact assessment, fisheries management and area protection at the state and regional level. The integration of ocean acidification into these planning and decision-making processes may lead to measures designed to reduce or mitigate ocean acidification (such as managing land runoff), or to measures intended to enhance the resilience of species or ecosystems so that they are able to more robustly withstand the impacts of a changing ocean $\mathrm{pH}$. To date however, climate change is only slowly being recognised as a factor to be considered in marine and fisheries decision-making, and ocean acidification has barely registered on the agenda of policy-makers. For example, in the North East Atlantic, the OSPAR Commission merely encourages Parties to gather baseline data on $\mathrm{pH}$ levels for monitoring 
Published as Karen N. Scott, "Ocean Acidification: A Due Diligence Obligation under the LOSC?” 35 (2020) International Journal of Marine and Coastal Law 382 - 408

purposes. ${ }^{129}$ Similarly, the 2013 Kiruna Declaration of the Eighth Ministerial Meeting of the Arctic Council also focuses on monitoring and assessment. In the Baltic Sea region, Recommendation 35/1 (2014), which sets out targets and the regulatory framework for establishing a system of MPAs, expressly refers to ocean acidification, but its impacts are not fully integrated into ocean planning processes. ${ }^{130}$ It is beyond the scope of this article to provide a detailed overview of such measures $^{131}$ but one or two examples relating to fisheries management and the designation of marine protected areas will be drawn on here to illustrate the potential of integrating ocean acidification considerations into decision-making and management processes, and the challenges in doing so.

First, in fisheries management, the impact of ocean acidification on target stocks and indeed the wider ecosystem is a relevant factor for decision-makers setting catch limits or adopting conservation measures. To date, regional fisheries management organisations (RFMOs) have paid little attention to ocean acidification, and climate change more generally is in the early stages of being actively considered as part of decision-making. One example of a more robust approach however, was adopted by the Commission for the Conservation of Antarctic Marine Living Resources (CCAMLR), which expressly recognised the threat posed by ocean acidification in 2009, and urged the Commission to consider the impacts of both climate change and ocean acidification in its decision-making. ${ }^{132}$ In 2015 an Intersessional Correspondence Group (ICG) was established in order to develop approaches to integrate the consideration of climate change impacts into the

\footnotetext{
${ }^{129}$ OSPAR Commission, JAMP Guidelines for Monitoring Chemical Aspects of Ocean Acidification HASEC 14/14/1, Annex 6 (2014). See also OSPAR Commission and ICES, Final Report to OSPAR of the Joint OSPAR/ ICES Ocean Acidification Study Group (SGOA) (2014).

${ }^{130}$ HELCOM Recommendation 35/1 (2014) System of Coastal and Marine Baltic Sea Protected Areas (HELCOM MPAs).

${ }^{131}$ But see Karen N. Scott, 'Integrated Oceans Management and Climate Change’ in Jan McDonald, Jeff McGee, Richard Barnes, (eds) Research Handbook on Climate Change, Oceans and Coasts (Edward Elgar, forthcoming 2020).

132 CCAMLR Resolution XXVIII Climate Change (2009).
} 
Published as Karen N. Scott, "Ocean Acidification: A Due Diligence Obligation under the LOSC?” 35 (2020) International Journal of Marine and Coastal Law 382 - 408

work of the Commission, with the particular task of making recommendations as to how the Commission can use information relating to climate change in its decision-making under Article II of the Convention, and how the Commission can consider climate change impacts across its agenda. ${ }^{133}$ However, at the 2018 CCAMLR Meeting, the ICG proposal to adopt a Climate Change Response Work Program (CCRWP) to further these goals ${ }^{134}$ failed to gain consensus, with two States expressing concerns that it duplicated work in other forums. ${ }^{135}$ Moreover, a separate initiative developed by Australia, Norway and the UK, which proposed a mechanism to communicate the nature and implications of known and potential climate change impacts in papers submitted to the Commission and Scientific Committee, ${ }^{136}$ was also rejected by the two same States. ${ }^{137}$ A number of members nevertheless committed to including climate impact statements in papers on a voluntary basis. ${ }^{138}$ Given that CCAMLR characterises itself as a conservationfocused rather than traditional RFMO, and that ocean acidification is known to have a disproportionate impact at the Poles, the challenges evident in creating meaningful policy within CCAMLR do not bode well for the integration of ocean acidification consideration into fisheries management more generally.

The second area where ocean acidification should be considered as part of planning processes is in the context of area-based protection. Designating marine protected areas (MPAs) may constitute a useful tool in protecting ecosystems vulnerable to ocean acidification, such as coral

133 Report of the Thirty-fourth Meeting of the Commission (CCAMLR XXXIV, Hobart, Australia, 19 - 30 October 2015) at [7.12].

${ }^{134}$ Report of the Thirty-seventh Meeting of the Commission (CCAMLR XXXVII, Hobart, Australia, 22 October - 2

November 2018) at $[8.7-8.10]$.

135 Ibid., at [8.11].

${ }^{136}$ Ibid., at [8.1 - 8.6].

137 Ibid., [8.3].

${ }^{138}$ Ibid., [8.5]. 
Published as Karen N. Scott, "Ocean Acidification: A Due Diligence Obligation under the LOSC?” 35 (2020) International Journal of Marine and Coastal Law 382 - 408

reefs, by minimising other threats, including fishing, extraction activities and tourism. The Great Barrier Reef Park is a high profile example of an MPA adapted through re-zoning in order to respond to ecosystem changes caused by climate change. ${ }^{139}$ Just as importantly, MPAs may be established as climate change refugia; areas where change is likely to be gradual or where the pristine nature of the ecosystem makes them particularly resilient to change and the MPA supports the maintenance of that pristine ecosystem. ${ }^{140}$ It is however, important to acknowledge the limitations of using MPAs as a tool to try to address ocean acidification. The most significant limitation is the deployment of a static place-based measure within a dynamic three-dimensional environment where ocean acidification is likely to change the nature of the ecosystem. Understanding variability in dispersal and connectivity is a key component of MPA network planning, ${ }^{141}$ and MPAs need to be part of a network to spread risk ${ }^{142}$ and of sufficient scale to protect ecosystem function. ${ }^{143}$ The challenges in responding to this criteria have been recently demonstrated by experience gained through designating MPAs in the North East Atlantic, where

${ }^{139}$ See the Great Barrier Reef Marine Park Authority, Great Barrier Reef Climate Change Adaptation Strategy and Action Plan 2012 - 2017) (Great Barrier Marine Park Authority 2012).

140 Bethany J. Harvey et al, 'Ecosystem-based management of coral reefs under climate change' (2018) 8 Ecology and Evolution $6354-6368$, at p. 6361.

${ }^{141}$ Melinda A Coleman et al, 'Anticipating changes to future connectivity within a network of marine protected areas' (2017) 23 Global Change Biology 3533 - 3542, at p. 3534. See also Mark H Carr et al, 'The central importance of ecological spatial connectivity to effective coastal marine protected areas and to meeting the challenges of climate change in the marine environment' (2017) 27 Aquatic Conserv. Mar. Freshw. Ecosyst. 6 - 29 and Javier Monzón, Lucas Moyer-Horner and Maria Baron Palamar, ‘Climate Change and Species Range Dynamics in Protected Areas' (2011) 61 BioScience $752-761$.

142 Brian D Keller et al, 'Climate Change, Coral Reef Ecosystems, and Management Options for Marine Protected Areas’ (2009) 44 Environmental Management 1069 - 1088, at p. 1070.

${ }^{143}$ Elizabeth McLeod et al, 'Designing marine protected area networks to address the impacts of climate change' (2009) 7 Frontiers in Ecology and the Environment 362 - 370, at pp. 363 and 365. 
Published as Karen N. Scott, "Ocean Acidification: A Due Diligence Obligation under the LOSC?” 35 (2020) International Journal of Marine and Coastal Law 382 - 408

it was found that area-based measures 'are by and large, not focused on areas where species and habitats are expected to be sharply impacted by' climate change and ocean acidification, and where there is low overlap between hotspots of change and current and planned MPAs. ${ }^{144}$

\section{Concluding Observations: Constraints and Opportunities of the Law of the Sea to}

\section{Address Ocean Acidification}

Ocean acidification has traditionally played a 'Cinderella' role compared to climate change more generally, and has been described as being relegated to little more than a 'footnote" ${ }^{145}$ within the UNFCCC regime until recently. This has created a significant structural constraint impeding an effective response in that neither the climate nor the law of the sea regimes directly address ocean acidification, or indeed provide a clear set of tools to do so. Ironically, the framework arrangement of LOSC, which in other contexts relies successfully on the incorporation of external standards and the application of those standards to LOSC Parties, arguably operates as an impediment or constraint in relation to ocean acidification. On the assumption that the UNFCCC regime and commitments made under the Kyoto Protocol and Paris Agreement respectively represent 'international standards' for the purposes of Article 212 of LOSC, Convention Parties could argue that compliance with their commitments under these instruments constitutes compliance with their obligations to address pollution under LOSC. While attempts have been made within multiple fora to bridge the climate - oceans regimes, and to adopt targets associated with ocean acidification, all are non-binding and ultimately, there is little evidence that they are

\footnotetext{
144 Ana M. Queirós et al, 'Solutions for ecosystem-level protection of ocean systems under climate change' (2016) 22 Global Change Biology 3927 - 3936, at p. 3932

145 J. Ekstrom and B. Crona, 'Institutional misfit and environmental change: A systems approach to address ocean acidification' (2017) 576 Science of the Total Environment 599 - 608.
} 
Published as Karen N. Scott, "Ocean Acidification: A Due Diligence Obligation under the LOSC?” 35 (2020) International Journal of Marine and Coastal Law 382 - 408

able to create obligations separate from and additional to commitments under the UNFCCC regime. Ultimately, although the 2015 Paris Agreement has established an overarching goal limiting temperature rise, there is no comparable goal under the Agreement or under any other binding instrument limiting $\mathrm{pH}$ change.

On the other hand, the law of the sea is a dynamic body of law and LOSC in particular is a living instrument, which has been described as able to 'grow and adapt to changing circumstances. ${ }^{146}$ The evolution of Part XII of LOSC from a set of obligations focused on pollution to a modern conception of marine conservation that expands on those obligations to include precaution, environmental impact assessment and area-based protection as well, demonstrates the vitality of the Convention. ${ }^{147}$ Consequently, it is argued her that the law of the sea should be interpreted and adapted to address ocean acidification irrespective of developments (or a lack thereof) under the UNFCCC. Returning to the argument made above, Parties to LOSC are subject to a due diligence obligation to take all measures to prevent, reduce and control pollution from any source ${ }^{148}$ and, in particular, from or through the atmosphere, ${ }^{149}$ and to protect and preserve rare or fragile ecosystems such as coral reefs. ${ }^{150}$ The UNFCCC provides no lex specialis in respect of $\mathrm{CO}_{2}$ emissions limits or a $\mathrm{pH}$ change target, and it is acknowledged that even full compliance with the 2015 Paris Agreement is unlikely to prevent or reduce ocean acidification. It is consequently disingenuous to argue that action under the Paris Agreement, in the absence of

\footnotetext{
146 Request for an Advisory Opinion submitted by the Sub-Regional Fisheries Commission (SRFC) (Advisory Opinion of 2 April 2015) ITLOS Case No. 21, Separate Opinion, Judge Lucky, at [18].

${ }^{147}$ See further Jill Barrett and Richard Barnes (eds), Law of the Sea. UNCLOS as a Living Treaty (BICL London 2016); Daniel Moeckli and Nigel D White, "Treaties as "Living Instruments"” in Michael J Bowman and Dino Kritsiotis (eds), Conceptual and Contextual Perspectives on the Modern Law of Treaties (CUP Cambridge 2018) 136 - 171. 
Published as Karen N. Scott, "Ocean Acidification: A Due Diligence Obligation under the LOSC?” 35 (2020) International Journal of Marine and Coastal Law 382 - 408

any specific consideration of the causes and impacts of ocean acidification, would constitute a due diligence approach a State Party's obligations under Part XII of LOSC.

Identifying the next steps, which logically follow from this conclusion, is however, not straight forward. Although LOSC provides for a conference of the Parties ${ }^{151}$ this does not traditionally deal with substantive matters and, in contrast to the UNFCCC COP, cannot create obligations for the States Party to the Convention or adopt resolutions interpreting individual provisions. Amendment is in theory possible, ${ }^{152}$ but in practice, unfeasible. A range of processes have been created in order to develop in practical terms the law of the sea, and to provide a forum for discussion and debate, but these do not in of themselves have a mandate to create binding obligations or even soft recommendations. Even UN-Oceans, which is an interagency collaboration mechanism on ocean and coastal issues within the UN system, and which has taken on a policy leadership role in relation to oceans and climate, including organising a number of joint events with the UNFCCC, has no mandate to developing binding rules.

One option is the adoption of a UN General Assembly resolution, which actually sets out a target for a reduction in $\mathrm{CO}_{2}$ emissions and/ or a global $\mathrm{pH}$ change limit (which may or may not be feasible from a scientific perspective). However, a General Assembly resolution is not binding - although it may be persuasive, as the example of bottom trawling and driftnet fishing demonstrate - and the General Assembly may be reluctant to engage in an area perceived to be under the jurisdiction of the UNFCCC. An alternative is the negotiation of an instrument or 'agreement' pursuant to LOSC on ocean acidification, or more sensibly, ocean acidification and climate change, but this is similarly unrealistic given that global negotiations for an agreement on biodiversity beyond national jurisdictions were initiated in 2018, and it is unlikely that States will have the appetite to initiate a set of parallel negotiations.

\footnotetext{
1511982 LOSC, Article 319(2).

1521982 LOSC, Articles 312 and 313.
} 
Published as Karen N. Scott, "Ocean Acidification: A Due Diligence Obligation under the LOSC?” 35 (2020) International Journal of Marine and Coastal Law 382 - 408

Ultimately, the most pragmatic and, in many ways coherent, way forward is the development of binding targets and measures under the UNFCCC regime, in conjunction with relevant maritime organisations such as UN-Oceans, to be applied consistently by Parties subject to obligations under both regimes. Meanwhile, if States are to comply with their due diligence obligation to prevent, reduce and control pollution arising from ocean acidification under Part XII of LOSC, they need to take action that targets ocean acidification in addition to or at least as part of their measures designed to address climate change. The 2015 Paris Agreement already provides a mechanism for the development of such measures, under the NDC process, whereby States themselves determine national actions that will contribute to achieving the overall aims of the Agreement. In addition, reducing ocean acidification comprises the target of a series of soft law instruments such as SDG 14.3, and these instruments were described above as performing an interstitial role, linking the regimes of application to the climate and the oceans. It might be argued that individual state action on ocean acidification, in pursuit of these soft law goals as well as States' due diligence obligation under Part XII of LOSC, can perform a similar interstitial role, linking and connecting the UNFCCC and LOSC in matters of climate change and ocean acidification. 